\title{
СОЦИАЛЬНАЯ ПОЛИТИКА: ПРАКТИЧЕСКАЯ ЭФФЕКТИВНОСТЬ ИЛИ НЕЭФФЕКТИВНОСТЬ
}

\author{
Тарасова Н.А., Васильева И.А.
}

В тексте кратко описаны результаты анализа параметров социальной политики: политики трудовых и предпринимательских доходов и их сокрытия, соотношения производительности труда и его оплаты, налогов, уровня сочиальных госрасходов, занятости населения. Эти результаты определяют, в основном, индикаторы социального неблагополучия сочиальной политики России. Лишь показатель вынужденной занятости определяет практическую эффективность политики занятости на микро- и мезоуровне экономики РФ в переходный и кризисные периоды.

DOI: $10.20537 /$ mce2020econ03

Результаты исследования динамики параметров социальной политики, сопоставленные с различными публикуемыми оценками, были получены в ЦЭМИ РАН в последние годы при очередной модернизации официальных и скрываемых показателей, рассчитанных в информационно-аналитической системе НДП («Население, доходы, потребление») по данным госстатистики [1]. С 2016 г. Росстат вел очередной пересчет данных с 1990 г.; в 2019 г. сообщалось о следующем пересмотре данных о доходах с 2013 г. Этот пересмотр, видимо, не внесет существенных изменений в предлагаемое рассмотрение характера ряда «неэффективных» параметров социальной политики (учитывая весьма критический характер официальных оценок экономической политики, опубликованных Счетной палатой в отчете по итогам стратегического аудита федеральных министерств и служб по 2019 г.). Система НДП создана на основе семиотической методологии обеспечения достоверности показателей (методологии СМОД/СМОГ) при моделировании финансирования социальной сферы РФ в расширенном ее понимании, т.е. с учетом взаимосвязей с производством. С помощью таких показателей решался ряд серьезных экономических задач в области политики доходов, в сфере труда и занятости, налоговой и жилищной политики, государственных расходов социального назначения - см., например, $[2,3]$ и др. Учиты- 
вая текущий пересмотр Росстатом данных с 2013 г., в настоящей работе активно использовались и имеющиеся оценки других организаций.

Как мы уже упоминали в докладе на 26-й конференции «Математика. Компьютер. Образование» в 2019 г. [4], эксперты консалтинговой компании New World Wealth в отчете 2016 г. сочли экономику России самой несправедливой, т. к. в РФ лишь $12 \%$ благосостояния были распределены на 143.5 млн граждан (наемные работники, получатели социальных выплат), а 88\% приходилось на долю долларовых миллионеров (62\%) и миллиардеров (26\%). Рассматривая чистый национальный доход РФ как совокупность оплаты труда и валовой прибыли экономики со смешанными доходами, эти доходы магнатов нужно относить к объему присвоения валовой прибыли, т.е. к предпринимательским доходам (Vп). Оставшаяся часть - это корпоративная прибыль, являющаяся показателем деятельности предприятий. Такая чистая прибыль корпоративного сектора РФ в 2017 г. упала на $8.5 \%$; и ранее (по расчетам в системе НДП за 2005-2014 гг.) реальная доля этой прибыли в валовой от 30$34 \%$ постепенно снижалась до $2.5 \%$ и ниже. В целом, по недавнему исследованию World Inequality Lab., разрыв между богатыми и бедными в РФ находится на уровне 1905 г. По ежегодному докладу (в конце 2018 г.) Общественной Палаты РФ, Россия занимает одно из 1-х мест в мире по неравенству в распределении богатства.

При этом в апреле 2019 г., по крупным и средним предприятиям, заработная плата (3П) у 50-71\% россиян была ниже средней ЗП (35 тыс. руб.), а у 10\% высокооплачиваемых работников - более чем в 13 раз выше, чем у 10\% низкооплачиваемых. Рост чрезмерной дифференциации доходов населения - когда ЗП верхнего квинтиля равна $48 \%$ всей оплаты труда, а медианная ЗП на $13 \%$ ниже средней, причем и ранее ЗП у 1.5 млн чел. была ниже прожиточного минимума (при МРОТ = ПМ лишь с конца 2017 г.) - не соответствует политике социального государства. Вместо поиска путей осуществления такой политики некоторые экономисты просто утверждают [5], что причина - выбор в 90-х гг. модели с низкой ЗП ради низкой безработицы, а не высоких ЗП при высокой безработице.

По рекомендации МОТ, минимальная ЗП должна быть не ниже 50\% средней; в России такая оплата в 11-14 раз ниже развитых стран. В РФ темпы роста МРОТ должны, учитывая рекомендации МОТ, существенно опережать темпы роста средней ЗП (до достижения хотя бы 30-33\% от нее) и допустимого децильного коэффициента дифференциации заработ- 
ков в 5-6 раз. Поскольку в РФ отношение производительности труда к его оплате $\left(\Pi_{\mathrm{T}} / 3 П\right)$ более чем вдвое превышает уровень развитых стран, обосновывается необходимость опережающего роста оплаты труда в ближайшие годы для его снижения. Наши расчеты (в т.ч. по приведенных акад. Д.С. Львовым почасовым данным) показали, что ПТ/ЗП во Франции, Италии, Японии, США, Канаде и Германии ниже в 2.2-3.7 раза, чем в РФ (у нас это 4.5). Рост ПТ некоторые противники усиления роли государства в экономике связывают только с активизацией бизнеса (улучшением делового климата при демократизации условий для него) [6], при этом игнорируются влияние и интересы сферы труда.

Добавим, что при выявлении в системе НДП всех скрываемых доходов $\left(\mathrm{V}_{\mathrm{C}}\right)$, а также верхней границы $\left(\mathrm{V}_{\mathrm{TC}}\right)$ для трудовых доходов и нижней $\left(\mathrm{V}_{\text {пс }}\right.$ для предпринимательских доходов (где $\left.\mathrm{V}_{\text {пс }}=\mathrm{V}_{\mathrm{C}}-\mathrm{V}_{\mathrm{TC}}\right)-$ величи-

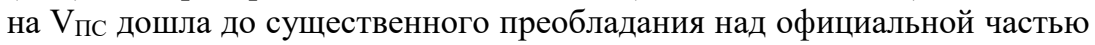
последних (в 2012-2013 гг. эта часть составляла не более 35\%). При этом в апреле 2017 г. глава Минфина А. Силуанов заявил, что «серый» объем ЗП (т.е. $\mathrm{V}_{\mathrm{TC}}$ ) превышает 10 трлн руб., и выход - изменение структуры налоговой нагрузки.

Что касается налоговой системы, неоднократно поднимался вопрос о прогрессивной шкале для НДФЛ, в том числе - по уровню даже не личных, а семейных доходов. Для их анализа можно использовать проведенные в системе НДП расчеты различных видов семейных доходов, в том числе с учетом разных видов ПМ: по официальным активным доходам либо с учетом их скрываемых частей. На основании показателей для 170 типов, совокупность которых практически охватывает все семьи, уже можно было бы вычислять объем НДФЛ по вариантам прогрессивной шкалы.

В расходах населения немалую роль играет оплата ЖКУ. Наш расчет годового денежного ущерба населения по сектору ЖКУ с 2000 г. показал, что ущерб населения по ЖКУ, вначале почти такой же, как по сектору прочих социальных услуг, за 10 лет вырос почти вдвое. К 2019 г., по мнению главы ФАС И. Артемьева, россияне по большинству позиций переплачивают за ЖКУ более $100 \%$.

Отставание России от развитых стран по уровню развития социальной сферы определяется во многом заниженным уровнем госрасходов социального назначения в РФ. В то же время, например, в Финляндии самый низкий для развитых стран уровень таких госрасходов сочетается с одной из лучших среди стран ЕС организацией государственной медицинской помощи, свидетельствуя тем самым, в отличие от нашей, о ее 
эффективности. В РФ же этот низкий уровень ухудшает здоровье населения - неудовлетворительность результатов реформы здравоохранения в РФ была признана осенью 2019 г. вице-премьером Т.А. Голиковой. И в образовании, и в здравоохранении «оптимизация» при «подушевом» финансировании, нацеленная на экономию госрасходов, может вступать в недопустимое для социального государства противоречие со смыслом и целью функционирования таких важнейших отраслей. Причем на октябрь 2018 г. в РФ, по исследованию Росстата, не были закрыты вакансии примерно на 50 тыс. врачей и столько же - на средний медперсонал.

В целом все сказанное выше означает, что рассмотренные параметры социальной политики определяют индикаторы практической неэффективности социальной политики (индикаторы социального неблагополучия). Вообще в наше время уровень и социального, и экономического развития страны далеко не в последнюю очередь зависит от развития науки. В национальном проекте о науке президент РАН А.М. Сергеев выделил в качестве второй (из трех главных) задачи РАН прогнозирование социально-экономического развития РФ. Для ее решения представляется необходимым периодически проводить обоснованный анализ динамики параметров социальной политики, что было начато нами ранее (см., например, [2]) и продолжается сейчас.

Особое внимание привлекает явление вынужденной занятости (В3), определившее единственный индикатор практической эффективности политики занятости в РФ в переходный и кризисные периоды на микрои мезоуровне экономики [7]. Это официальная занятость (нередко с пониженной оплатой) наемных работников, которую работодатели - в основном, государство, - вынуждены сохранять ради предотвращения массовой безработицы, опасной в «нестабильных» условиях России (переходный период или кризис), т.к. чреватую социальными взрывами. Это обеспечивает условия для сохранения и затем развития экономики России. В госстатистике уже в 1994 г. был принят расчет неполной занятости ВЗ. По итогам мониторинга ИНСАП РАНХиГС за 2016 г., за 4 года кризиса это охватило уже до $10.7 \%$ сотрудников. Позднее Росстат этот вид В3 называл «неполной видимой занятостью». Встречающееся использование термина «частичная безработица» [8] некорректно, т.к. определение безработицы (официально или по МОТ) подразумевает вообще отсутствие какой-либо занятости.

Хотя В3 была замечена и проанализирована еще в 1993-1994 гг. [9], в ряде работ сотрудников ВШЭ (и ЦеТИ ВШЭ) много лет не В3, а низкая 
оплата труда рассматривалась как «первопричина» предотвращения массовой безработицы, что до сих пор называется этими авторами «ненормальностью» нашего рынка труда. По оценке главы Экономической Экспертной группы Е.Е. Гурвича в докладе на XXVIII международной Апрельской конференции (Москва, ВШЭ, 2017 г.), этот «диагноз» подобен неквалифицированному диагнозу врача, выдающего симптом болезни за такой диагноз. Даже упоминая в последние годы хотя бы о вынужденной неполной занятости, на недавнем докладе в Центре стратегических разработок ВШЭ (по обследованию отсутствия роста безработицы при кризисе в России) авторы вновь говорят не о разумной в условиях России специфике рынка труда, а все о той же его «ненормальности» (что охотно подхватывают СМИ) — видимо, по-прежнему считая нормой лишь преобладавшую ранее «мейнстримовскую» точку зрения.

Процесс заметного сокращения масштабов В3 шел ранее благодаря оживлению экономики РФ после кризиса 1998 г.; но кризис 2008 г. вновь вызвал рост В3 и даже переход ее на уровень моногородов (т.е. мезоуровень экономики) при угрозе их ликвидации. После ряда публикаций с 2009 г. по этой проблеме, в том числе в журнале «Власть» [7], и совещаний с губернаторами по планам развития занятости, к 2017 г. была принята государственная приоритетная программа развития моногородов в 2016-2025 гг., в которой предусматривалось их многопрофильное развитие. Эта в общем благая цель выразилась, в частности, и в привычно-командном стиле - в запрете (для вновь создаваемых предприятий) на совпадение кодов ОКВЭД (точнее - первых 2 цифр из 6) с кодами «старых» градообразующих предприятий. Судя, например, по выступлению главы городского округа Мантурово М.В. Блинова на 18-ом Всероссийском симпозиуме «Стратегическое планирование и развитие предприятий» (Москва, ЦЭМИ РАН, апрель 2017 г.), возможности местных властей были серьезно затруднены подобным ограничением, препятствующим созданию каких-либо сопутствующих производственных предприятий рядом с прежним, но уже серьезно модернизированным (и потому уже вполне работоспособным) градообразующим предприятием. Оттуда ранее и были уволены работники, многие из которых пошли бы работать на «родственные» предприятия (с учетом их профессиональной подготовки и опыта предыдущей работы). По разным причинам высвободившиеся в результате модернизации основного предприятия работники далеко не всегда хотели или могли — в том числе по личным характеристикам заниматься предпринимательством, заводить собственный бизнес (что 
практически диктовалось указанной выше приоритетной госпрограммой). Это распространенное явление относилось к такой части В3, как «вынужденные предприниматели», принуждаемые властями к «выбору» между предпринимательством и практически недоступной работой по найму. Естественно, диктуемый властями по госпрограмме «принудительный» путь предпочтительнее было бы заменить приобщением высвобожденного населения к предпринимательству каким-либо экономическим (социально-экономическим) путем.

В целом же, по упомянутому в начале статьи выводу Счетной палаты, принятые по этой госпрограмме меры не решили ключевую задачу (улучшение роста благополучия жителей), и летом 2019 г. уже был подготовлен проект новой госпрограммы на 2019-2024 гг., который должен быть уточнен к июню 2020 г.

В заключение проведенного содержательного анализа динамики параметров социальной политики в РФ отметим, что характер почти всех показателей говорит о практической неэффективности сочиальной политики, т.е. о социальном неблагополучии. Исключение составляет один показатель - вынужденной занятости. Для условий России (если не ограничиваться сугубо «мейнстримовским» критерием прибыльности) его нужно оценить положительно как индикатор практической эффективности социальной политики занятости: на микроуровне и (при кризисе) мезоуровне экономики - как средство предотвращения работодателями (в основном, государством) недопустимой (экономически, социально и политически) в условиях РФ массовой безработицы; кроме того, на мезоуровне экономики — и как средство обеспечения государственной целостности и сохранения геополитической безопасности страны.

\section{СПИСОК ЛИТЕРАТУРЫ}

1. Тарасова Н.А., Васильева И.А., Сушко Е.Д. Использование системы НДП (Население, доходы, потребление») для оценки социальной политики // Россия и современный мир, 2011. №3. С.182-193.

2. Tarasova N. et al. Analisys of the Social Policy Parameters by Forecasting Indicators of Social Sector Financing // Studies on Russian Economic Development. 2009. N.5. P. 495-505.

3. Тарасова Н.А., Васильева И.А., Фонтана К.А. Решение экономических задач на основе системы НДП («Население, доходы, потребление») при 
анализе и оценке параметров социальной политики // Современные проблемы соииально-гуманитарных наук, 2016. №2(4). С. 168-172.

4. Тарасова Н.А, Васильева И.А. Политика бизнес-менеджмента и семиотический контроль динамики присвоения валовой прибыли // Анализ и моделирование экономических и социальных процессов / Математика. Компьютер. Образование: Сб. научн. трудов. Выпуск 26. - М.-Ижевск: НИЦ «Регулярная и хаотическая динамика», 2019. С. 158-163.

5. Зарплатное неравенство: сколько и где официально зарабатывают россияне // РБК. URL: https://www.rbc.ru/economics/20/07/2019/5d317d739a7947d7fa1672a3

6. Ясин Е.Г. Догоним - не догоним? // Российская газета, № 3 от 10.01.2014. С.5.

7. Тарасова Н.A. Роль вынужденной занятости в России переходного и кризисного периодов // Власть, 2011. № 2. С. 92-96.

8. Экономисты рассказали о главном свойстве рынка труда в России // РБК от 12.04.2017. URL:

https://www.rbc.ru/economics/12/04/2017/58ee20959a7947d3b22d17b0

9. Lvov D., Tarasova N. Latent unemployment in transition: Phenomenon of involuntary employment in Russia // C.U.R.E. Challenges of Unemployment in a Regional Europe. - Netherlands: Friske Akademy, 1994.

\section{SOCIAL POLICY: PRACTICAL EFFECTIVENESS OR INEFFICIENCY}

\section{Tarasova N.A., Vasilieva I.A.}

The paper briefly describes the results of the analysis of the parameters of social policy: the policy of labor and entrepreneurial incomes and their concealment; the ratio of labor productivity and labor pay; taxes; level of social government spending; employment of the population. These results are determined mainly by indicators of the social disadvantage of Russia's social policy. Only the indicator of involuntary employment determines the practical effectiveness of employment policies at the Russian microeconomic and mesoeconomic levels of in transition and crisis periods. 